\title{
Branch Retinal Arterial Occlusion
}

\author{
Subedi $S^{1}$, Shrestha $C^{2}$ \\ 1,2 Department of Opthalmology \\ NAMS, Nepal Eye Hospital, Nepal
}

\section{Corresponding Author}

Dr Sudesh Subedi

Nepal Eye Hospital

Email.ssubedi63@rediffmail.com

Kathmandu Univ Med J 2010;9(32):423-5

\begin{abstract}
Retinal arterial occlusion is an ocular emergency in which visual prognosis is poor mostly due to late presentation of the patient and macular involvement. The casee described, in this report is ane incidence of Branch Retinal Arterial Occlusion in a 22 year old female with grade II Mitral Regurgitation. The patiente presented witha complaint of painless, diminution of vision in the right eyn. She alsod presented with perception of black shadow in the superior visual fiel $\mathrm{n}$ of the same eye 5 for five days. There was no significant systemic ord personal history. Her visual acuity at presentation was $6 / 60$ and 6/6 in the right and left eyes,y which did not improve with glasses or pin-hole. Anterior segment including papillary reaction was normal in both eyes while Fundus examination of the right eye revealed retinal whitening inside the inferotemporal vascular arcade that was encroaching foveolar avascular zone. Visual field defect was detected at superonasally inside arhade but Fundus Fluorescence Angiography was normal. An echoycardiograph revealed grade II Mitral Regurgitation. The patient was kept on observation and after two2 days of follow-up, vision in the right eye was improved to 6/6 unaided but visual field defect was remained same.
\end{abstract}

\section{Key Words}

branch retinal arterial occlusion, cardio valvular disease, visual field defect.

\section{INTRODUCTION}

Retinalarterialocclusivediseaseisanocularemergency whichcanmanifestinanumberofclinicalfashions ${ }^{1}$ such ase central retinal arterial occlusion (CRAO), branch retinal arterial occlusion (BRAO), cilio-retinal arterial occlusion, combined CRAO and veins occlusion, and cotton-wool spots. Among the cases of acute retinal arterialobstruction, CRAOaccountsforapproximately 57\%,BRAOfor $38 \%$, andcilio-retinalarteryocclusionfor $5 \%{ }^{1}$. The visual prognosis in eyes with BRAO is usually quitegoodunlessthefoveolaiscompletelysurrounded byretinalwhitening.Suchaconditionneedstreatment withaggressionasinCRAO. Patientswithretinalarterial occlusionshouldundergodetailedsystemicevaluation including cardio-valvular.

\section{CASE REPORT}

A22yearoldfemalepresentedtotheretinaclinicofNepal Eye Hospital had a chief complain of painless sudden diminution ofvisionand perception ofblackshadowin superior visual field of right eye since 5 days. It was not associatedwithredness, photophobia, watering,painon ocularmovement,floatersandflashesoflightorcoloured haloes.Shehadnosimilarepisodesinpast.Therewasno history of ocular trauma, glaucoma, diabetes mellitus, hypertension,cardiovasculardisease,bleedingdisordersor highmyopia.Thepatientewasnotunderanymedicatiosc whichmayhavecontributedtohercondition. Ongeneral examinationshewasofaveragebuiltandwellorientedto timeandsurroundings. Herbloodpressurewas 100/8mm of $\mathrm{Hg}$ with regular pulse of 72 beats per/minute.

Examination revealedthatherextra-ocularmovement, convergenceandcovertestwasnormal.Unaidedvisual 
acuity was $6 / 60$ and $6 / 6$ in the right eye (RE) and left eye(LE) respectivelyandwasnotimproving withglasses orpin-hole.Slit-lampexaminationofanteriorsegment revealed normal findingsin botheyes(BE) with normal papillaryreactions.Slit-lampbio-microscopicexamination with +90 .D lens revealed clear ocular media in $\mathrm{BE}$ with normal fundus findings of the LE but on RE fundus it revealednormaldiscwithmilkywhiteretinaencroaching thefoveolaravascularzonearoundtheinfero-temporal vascular arcade (Figure 1).

There was no retinal haemorrhaeing, exudates or arteriolar attenuation. Goldmann visual field showed paracentralrelativeandabsolutescotomainsupero-nasal region, partially involving themaculararea(Fig2a).On Goldmannapplanation,Intraocularpressure(IOP)was 1 $\mathrm{mm}$ of $\mathrm{Hg}$ in BE. Colour vision was tested with Ishihara polychromaticplatesanditwasnormalinBE.Adiagnosis ofrighteyeinferotemporalbranchretinalarterialocclusion was made.

ABbloodtestsuchaseTotalcount $\left(8000 / \mathrm{mm}^{3}\right)$,differential count(neutrophil-70\%,lymphocytes-27\%,eosinophil $3 \%$ ), haemoglobin(12gm\%),erythrocytesedimentation rate $(14 \mathrm{~mm} /$ in first hour Wintrobe method), blood sugar(fasting-70mg\%and postprandil-130mg\%)was normal. Rheumatoidfactors and antinuclearantibody werenegative.Lipidprofileshowedcholesterol-143mg\%, HDL-36mg\%,LDL-79mg\%andTriglyceride-139mg\%. ThecardiacconsultationrevealednormalECGbutgrade II Mitral Regurgitation in echocardiography. Two days afterthecardiacconsultation,thepatientfollowedupher consultationatadifferenneyehospitalandunderwenta visualacuityandGoldmannvisualfieldtestagain.These testsshowedimprovementoftherighteyevisualacuity from previously being $6 / 60$ to $6 / 6$ unaided, while the

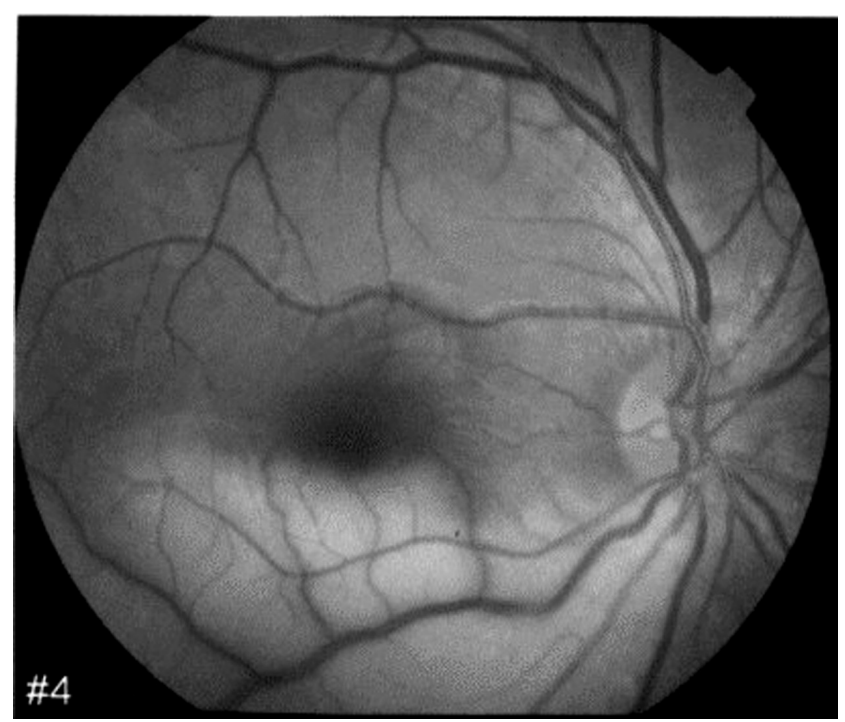

Figure 1. RE Fundus showing inferotemporal BRAO with retinal whitening previouslypresentrelativescotoma(visualfield defect) hadsubsided,thougtparacentralabosolutescotomawas persistent.

Thiscaseisreportedforrarityofvisualimprovementafter a week of BRAO in young women.

\section{DISCUSSION}

Retinal arterial occlusive (RAO) disease is an ocular emergencyasitisassociated withprofoundvisuallossdue tothemacularinvolvementandasmostofthmdiagnosed casesarepainlessandsudden.Thereareseveralocularand systemic conditions ${ }^{1}$ associated with RAO. The mostg common conditions are as follows:

a. Abnormalities contributing to embolus formationse.g.cardiacvalvulardisease,systemic arterialhypertension,carotidatherosclerosis,or left ventricular hypertrophy.

b. Traumasuchaseretrobulbarinjection,ororbital fracture repaic.

c Coagulopathiessuchaskesicklecelldisease, homocystinurea,oralcontraceptives, platelet abnormalities, proteinSdeficiency,orproteinC deficiencyc.

d Collagen vascular disease.

e. Ocularconditionssuchaseincreasedintraocular pressure, toxoplasmosis, opticneuritis, optic disc drusen, prepapillary arterial loops etc.

TherearereportedcasesofBRAOinsyphilis² (thirdstage) andcasesalsobeenreportedafterintra-vitrealinjections of Lucentis and Avastin (Anti VEGF). ${ }^{3}$ Similarly, BRAO is observed in patients who suffer from migraines, hypotension oro use nasal oxymethazoline'

The causes of RAO in patients under the age of 30 years often differ from those inr patients olders. Some of theDdiseaseentitieswhichtmorecommonlycauseRAO inyoungindividualsincludemigraines,cardiacdisorders, trauma,sicklinghemoglobinopathies,ocularabnormalities (opticnervedrusenandprepapillaryarterialloop),protein $\mathrm{C}$ and $\mathrm{S}$ abnormalities and antithrombin III.

Overall, patients with acuteRAO whoareyoungerthan 45yearsofagearethreetimesmorelikelytohavecardiac diseasesthatrequireanticoagulationorcardiacsurgery. ${ }^{1}$

In CRAO the visual acuity may range from counting fingers to light perception. Overall, in $90 \%$ of eyes, the visual prognosisispoor.ButinBRAOthevisual prognosis isd relative both at presentation and at the final visit ${ }^{4}$ 
unlessfoveolaisinvolved.Approximatelyt80\%ofpatients' eyeseventuallyimproveto20/40orbetter, althoughthe residualfielddefectsgenerallyremais. ${ }^{1.5}$ ASsimilarresult was observed in our case; the vision was improved to 6/6 (unaided) without treatment while the visual field defectwaspersistent. Retinalarterialocclusioninvolving maculaisanocularemergencyanditrequiresimmediate treatment to reduce the IOP as soon as possible. These treatmentsareocularmassage,para-centesis,intravenous mannitol, inhalation of mixture of $\mathrm{O} 2$ (95\%) with $\mathrm{CO} 2$ (5\%), useofAnti-fibrinolyticagentandtrans-luminalNdYAG embolysis/embolectomy6.

Although the visual outcome is determined by factors suchasthecauseofarterialocclusion, natureofocclusive emboli and duration of retinal ischemia ${ }^{7}$, aggressive treatmentmayre-establishretinalcirculationandimprove the visual outcome.

\section{CONCLUSION}

Thecausesrofretinalarterialocclusion inyoung adults arsdifferentfromthoseofolderindividualsamongwhich cardio-valvular disease is an important factor. Visual prognosis is good in BRAO.

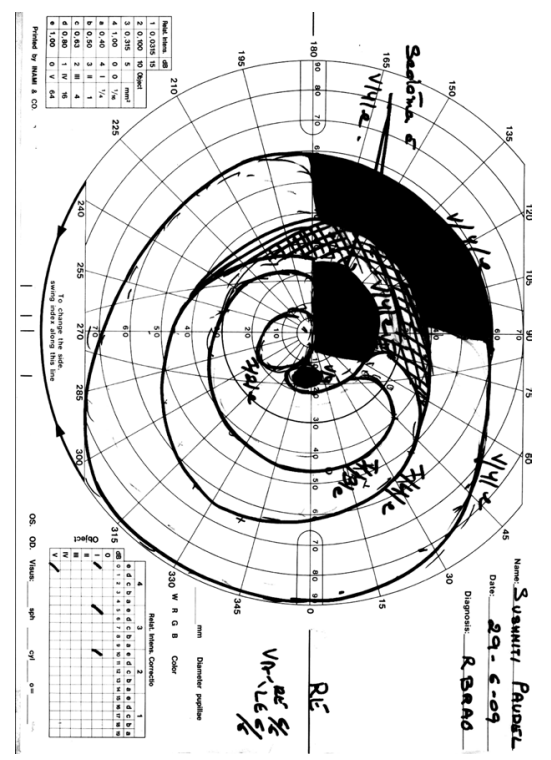

Figure 2a. Visual field on the day of presentation absolute scotomasurrounded by relative scotoma which is further surrounded by absolute scotoma in the superonasal visual field

\section{REFERENCES}

1. Sharma S, Gary C. Brown.Retinal arterial obstruction. In Text book of Retina. Volume II. Stephen J. Ryan. 3rd ed. p.1350-64.

2. GuberJ,SchneiderUetal.Unilateralocclusionoftheretinal arterybranchandretinawhitedots.Ophthalmologe2009 Dec;106:1130-4.

3. Von Hanno T, Kinge B, Fossen K.Retinal artery occlusion following intravitreal anti-VEGF therapy. Acta Ophthalmol 2010;88:263-6.

4. Yuzurihara D, Lijima H. Visual outcome in central retinal andbranchretinalarterialocclusion.JpnJOphthalmol2004: 48:490-92.

5. Mason JO 3rd, Shah AA et al. Branch Retinal Arterial occlusion:visualprognosis.Am.JOphthalmol2008;146:4557.

6. OpremcakE,RehmarAJetal.Restoration of retinalblood flowviatransluminalNd-YAGembolysis/embolectomyfor central and branch RAO. Retina 2008;2:226-35.

7. Shimon Rumell, Uri Rehany et al. Aggressive systematic treatment for CRAO. Am J ophthalmol 1999;128:733-8.

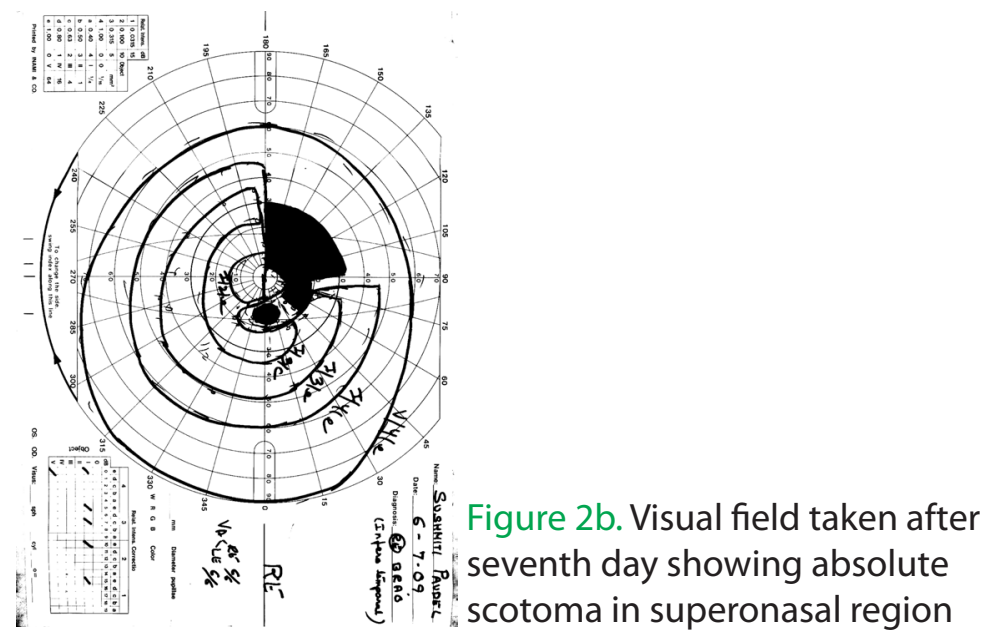

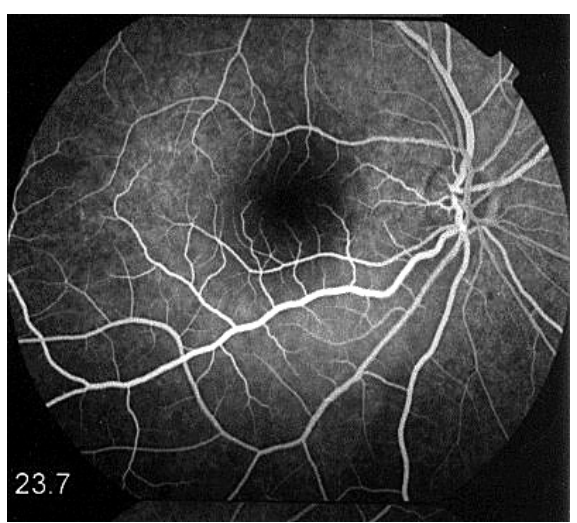

Figure 3. RE Fluorescein angiography showing thrombus near the inferior margin of the disc with perfused macula 